\title{
Traffic Conditions in Emerging University Campuses: King Saud University, Riyadh, Saudi Arabia
}

\author{
Musaad Al-Mosaind ${ }^{1}$ \\ ${ }^{1}$ Department of Urban Planning, King Saud University, Saudi Arabia \\ Correspondence: Musaad Al-Mosaind, Department of Urban Planning, King Saud University, Saudi Arabia. \\ E-mail: almosaind@yahoo.com
}

Received: October 7, 2014 Accepted: October 19, 2014 Online Published: November 27, 2014

doi:10.5539/jsd.v7n6p204 URL: http://dx.doi.org/10.5539/jsd.v7n6p204

\begin{abstract}
Universities worldwide face growing problems of traffic congestion and parking shortages due to the increased usage of private automobiles and the decline of public and non-motorized transport systems. This paper addresses transportation system challenges facing university campuses. As a case study, it addresses King Saud University, Saudi Arabia. The fast growth of King Saud University Campus during the last 5 years had profound impacts on its transportation system.

The study adopts two methodological approaches. Theoretically it reviews and analyzes several studies and published reports related to KSU campus and other international campuses. The empirical approach emphasizes the analysis of field data gathered by relevant KSU departments. The paper intends to analyze changes in traffic conditions and transportation systems within the KSUC and draw conclusions on the current and future issues facing the campus and other similar campuses.

For a more sustainable campus, KSU has to adopt a balanced transportation system. The new system should not be based solely on improving vehicular circulation and parking provisions. It should enhance public transportation and pedestrian environment within the campus. The university should embark new sustainable policies to curtail demand on vehicular trips and parking spaces and increasingly rely on environmental-friendly modes of travel.
\end{abstract}

Keywords: university campuses, traffic conditions, transportation issues, sustainable transportation, traffic demand management, parking policies, traffic surveys, ITS, public transportation, pedestrian movement

\section{Introduction}

Planning major university campuses has been a real challenge in recent years. Today's campuses have become as complex as urban areas. Because of their unique characteristics and inter-related influences, most main universities' campuses are planned as small cities/communities (Coulson, et al., 2011).

Big universities worldwide face growing problems of traffic congestion and parking shortages. The increased usage of private automobiles and the decline of public and non-motorized transport systems are the main causes of these outcomes (Toor \& Halvlick, 2004). Historically, plans for university campuses assume low incoming traffic and high non-auto related trips. The presence of Staff and Student housing is a norm in almost all universities. The exception is for those universities located in city centers due to limited spaces and high land prices. The worldwide trend of increased automobile usage, observed in most developed and developing countries are the main reason for the growing transport problems for most university campuses.

Meanwhile, university campuses within cities are important trip generators for young population and professionals. They ought to be closely linked to their major transport systems. They significantly contribute to the high level of work and school trips during the day, especially during peak hours. Cities like Riyadh which houses three big public universities and 5 private universities ought to consider these campuses as significant trip generators in their structure plans.

\subsection{Problem Definition}

This paper addresses transportation system challenges facing university campuses. As a case study, it addresses King Saud University, the largest and most prominent university in Saudi Arabia. The fast growth of King Saud 
University Campus during the last 5 years had profound impacts on its transportation system. The university transportation system is assessed in light of its development to devise the needed policies to mitigate negative growth externalities. In particular, the paper discusses the following issues:

1) The continuous growth of KSUC facilities with no proper transportation policies to tackle the increasing problems of campus traffic congestion.

2) Most Students, staff and faculty members are dependent on private automobiles in their daily commute to and within the university campus.

3) University entrances and parking stalls may not cope with growing problems of traffic congestion and parking shortages.

4) The lack of viable public transport within the city and proper traffic and parking management systems within the campus.

5) No significant walking trips within the campus especially for students and staff internal trips.

\subsection{Research Objectives \& Methodolgy}

There are three main objectives for this research:

- $\quad$ To examine existing and future traffic conditions inside KSU campus and the potential impacts of the big university projects due soon for completion;

- $\quad$ To suggest solutions to alleviate potential traffic congestion and manage traffic to and within the campus in the short and long run.

- $\quad$ To devise transportation policies for university campuses to tackle the ever-growing transportation problems facing them.

The study adopts two methodological approaches to address these objectives. Theoretically, the study will review and analyze several studies, published reports and projects and case studies related to KSU campus and other local and international campuses. The empirical approach emphasizes the analysis of field data gathered by relevant KSU departments for different studies, including traffic counts collected at two time frames (2008 \& 2010). The paper intends to analyze changes in traffic conditions and transportation systems within the KSUC and draw conclusions on the current and future issues facing the campus and other similar universities' campuses.

\section{Literature Review}

Dealing with campus transportation systems has become a challenge and, sometimes, a nightmare for many universities. The growing problems of traffic congestion, inadequate public transportation, parking shortages and pedestrian safety are some of the long list of challenges facing universities today (Coulson, et al., 2011; Burgstahler \& Cory, 2008; Toor \& Halvlick, 2004).

Old Universities found as early as the $9^{\text {th }}$ century in the Arab world are located within or around the largest mosque in the city center. Examples include the University of Al-Karaouine (859 G), Al-Azhar University (970-972 G) and Al-Nizamiyya (1065 G) (Note 1). On the other hand, many older universities in the western world were developed in agricultural areas near thriving cities (Coulson, et. al., 2011). In later times, cities grew to enclave nearby campuses and/or universities started to expand to surrounding areas.

As universities grew in numbers (students and staff) and diversified their activities, coupled with increases in vehicle ownership and usage, their current campuses were not able to cope with these emerging problems. Most urban university campuses are facing problems of traffic congestion and parking shortages (Toor \& Halvlick, 2004; Kaplan \& Clapper, 2007).

University campuses have unique congestion characteristics. Traffic patterns are influenced by various movements from faculty and staff, students and visitors to the different campus activities, in addition to their external trips to other functions (Kaplan \& Clapper, 2007). These movement patterns differ in time and space. Most congestion problems in university campuses occur around campus gates (if present) or near parking facilities. University campuses experience different travel peak hours related to their physical layouts, university operations and class scheduling.

Tackling these problems has become universal. Most campus plans emphasize maintaining a high quality environment for its students and staff in order to be competitive with other local and international universities. Vehicular circulation has become a priority for many universities, sometimes on the cost of pedestrian movement (Coulson, et al., 2011). Meanwhile, other universities have emphasized the importance of pedestrian network in 
linking various university activities. Improved public transport to support pedestrian movement is the most sustainable solution for university campuses worldwide (Toor \& Halvlick, 2004; TCRP, 2001; Burgstahler \& Cory, 2008). In fact, most universities have provided unlimited funding for public transport systems to allow all users to afford them. This strategy has succeeded for many urban universities in two aspects. It increased mobility options for all users. It also helped cities and communities near campuses in reducing traffic and parking needs (TCRP, 2001).

Further, most universities have adopted Campus-wide Transportation Plans to tackle the ever growing traffic congestion within their campuses. Plans range from strategic policies and solutions to localized initiatives and mitigation techniques. Comprehensive Plans emphasize the importance of campus sustainability through devising multi-modal transportation systems and extensive reliance on demand management techniques (HDR, 2012; Norton, et al, 2007; Zalkaw \& Renkens, 2010; Kaplan \& Clapper, 2007). Meanwhile, various initiatives were put in place for many universities to tackle short-term congestion problems such as dedicated bus routes to and within campuses, campus ridesharing, bicycle commuting programs and green campuses for walking (Mallia, 2011; Durr, 2011; Slade, 2010; Davis, 2011).

\section{Case Study: KSU Campus}

King Saud University was founded in 1957. Throughout its fifty-six year history, KSU has grown into the oldest and most premier University in the Kingdom.

There were originally 21 students taught by nine professors. In 1960, KSU had grown to 541 students. In the 2004-2005 academic year, the total enrollment of all KSU (male and female) graduate, undergraduate, higher diplomas and junior diploma programs reached well over 80,000 students. Academic staff was over 3000 and administration, technical staff, medical staff and labor in the University and Hospitals was over 8000 . These totals reflect both students and staff located on the main KSUC campus and off campus locations.

The university was originally spread over various buildings located throughout the City of Riyadh. In 1982, the university moved to its new campus housing all male academic facilities and its main educational hospital. KSU Campus (KSUC) is located nine kilometers northwest of Riyadh City Center in Al-Deriyah district. The campus is approximately 9 square kilometers. The University has seen great expansion over the past several years with the introduction of new facilities, an increase in students, faculty, and staff members, and an increase in the number of people referred to the hospital. Future developments planned or committed for the University include a new Girls' University Campus, expansion of King Khalid University Hospital and medical services, endowment projects, new research facilities, new college buildings, sport complex and new housing complexes.

Accommodating these future activities should be accomplished in a way that sustains and makes improvements to existing transportation system such as traffic flow (both pedestrian and vehicular), traffic circulation and parking using the available resources within the campus. The growth of students and faculty and the continuous growth of King Khalid University Hospital (KKUH) have made it necessary to reevaluate the transportation system for existing and future conditions.

\subsection{Overview of Existing Conditions}

The rapid growth of KSUC and King Khalid University Hospital (KKUH) has given rise to problems and challenges for the university transportation network (see Figure 1). It is no surprise that Parking and Traffic operations have been a concern for KSU administration for many years. Studies attempting to assess and evaluate the problem as well as suggest recommendations and solutions have focused on all aspects of the transportation network, including (but not limited to): traffic safety, parking and traffic operations (Anani et. al., 1989; Al-Mansour \& Zaho, 2004; Al-Fawzan, 2004; Al-Jowair, 2006).

The original KSUC Master Plan has called for an overall enrollment of 18000 students (Deputy for Projects, 2009). Accordingly, the plan redesigned road network and parking facilities to accommodate the corresponding traffic demands. Meanwhile, it limited capacity of KKUH to one main hospital building accommodating both in-patients and out-patients visitors. Later, the university constructed a new building for out-patients clinics allowing the hospital to double its out-patient visitors. Currently, the total number of students enrolled has reached 34000 students. This has exerted huge pressure on existing road network and parking facilities within the KSUC. 


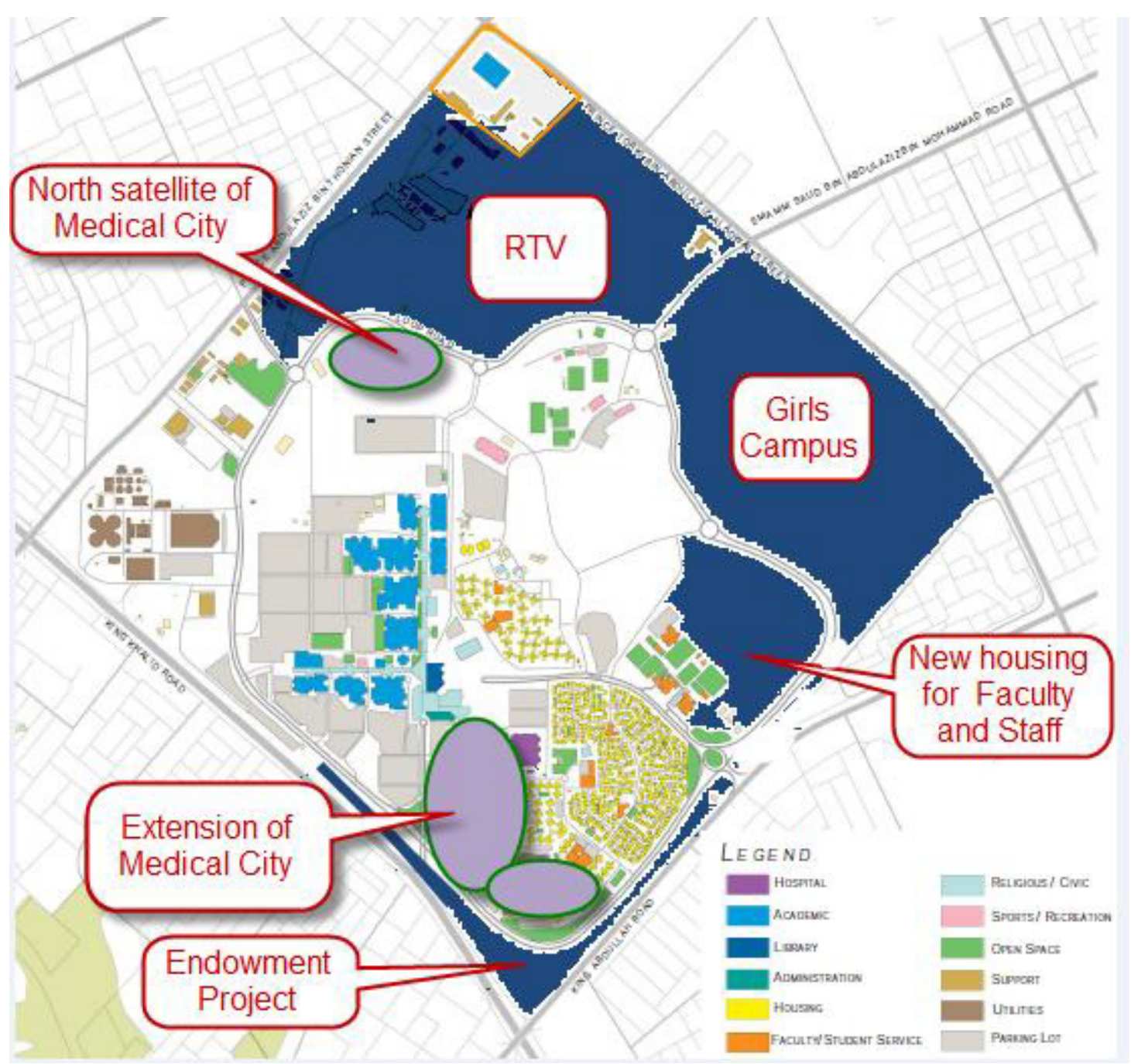

Figure 1. KSU Campus existing and future land uses

Source: Deputy for Projects, KSU Master Plan Update, 2009

Traffic congestion, inadequate parking and unattractive urban environment have become the main problems facing KSUC. The problems that arise at peak hours not only delays traffic on campus; it spreads the problems on surrounding roads leading to the campus. Anani and others (1989) concluded that changes in Riyadh transportation network directly affects traffic patterns at KSUC. They found that the peak hour experiencing a delay on campus was between 7:00-8:00 AM, similar to the city peak hour. By using multiple analyses (origin-destination surveys, traffic volume analysis, questionnaires and analysis of arrival times and final destinations) they concluded that the most congested entrance points are the Emergency and Book gates, and there is queuing of vehicles at these access points. Also, most parking lots, especially at the university center, do not have the capacity to fulfill the demand.

An additional source of congestion within the KSUC campus can be directly related to the lack of parking and traffic management. Increases in number of students and employees require additional parking provisions especially in some bottleneck areas. Al-Mansour and Zaho studied parking conditions throughout the campus in order to come up with improvement scenarios (Al-Mansour and Zaho, 2004). Analyzing capacity and demand, in addition to parking layouts, number of entrances, exits and additional space surrounding parking lots proved the problem. Overall Demand far outweighs capacity.

\subsection{KSU Campus Future Plans}

As the University grows in size and space, the needs of its students, faculty and staff and visitors are changing. Fully understanding the future growth of King Saud University would help make the right decisions regarding circulation and parking within the University. Major projects completed or due for completion soon include the 
following:

\section{1) Girls' University Campus}

The campus (when fully developed) is going to house a population of over 27,000 female students and 4,000 female teaching staff and employees. The Girl's campus is not internally connected to the main campus of King Saud University, except a shuttle service to the KKUH for female medical students. A university study suggests that the new campus will generate approximately 5,200 cars per hour and 400 busses per hour (Deputy for Projects, 2006). This impact, on top of the KSUC traffic, will need to be considered in the analysis and future planning of the surrounding road network.

2) Riyadh Techno Valley

Riyadh Techno Valley (RTV) aims to advance university research activities in areas of the knowledge economy. The valley will house major research centers for large private firms, other government research centers, some university research institutions, 2000 dwelling units, and 1.2 million sq. meters of office space.

\section{3) KSU Medical City}

In addition to King Khalid University Hospital, KSU Medical City is expanding due to the growing needs of medical students, staff and patients. Project expansions planned for the Medical City include 6 medical facilities and Boys' Medical College Expansion. This growth of the Medical City will have a significant impact on the transportation network not only within the University campus but to surrounding road network.

\section{4) New Housing Complexes}

The new housing complex within the campus will house nearly 1400 families. Further, the new Medical City Plan incorporates the construction of a new housing complex for nearly 5000 nurses and medical staff.

\section{5) Endowment Project}

The Endowment area, planned as a special business district, covers a land of 213,000 square meters. Buildings' land uses include a convention center, retail facilities, two high class hotels, residential suites and offices. Future population of endowment project will reach 23,000 persons including employees and residents.

\section{6) Sport City Complex}

The new sport complex includes a big stadium for 20,000 spectators, a multi-sports auditorium for 5000 spectators, an Olympic size swimming pool, and an academic building for the College of Physical Sciences.

These projects would have a profound impact on the university size in terms of population and land uses. Table 1 shows the massive growth of the total numbers of students, faculty and staff upon the completion of these projects. The total campus population would increase from 46000 persons five years ago to more than 136000 persons. The number of occupied dwelling units will increase from 1100 units to less than 8000 units. Similarly, the total floor area of future buildings would triple in the next 15 years. Extensive efforts have to be undergoing to achieve the required parking spaces estimated at 54000 lots. This growth would exert extensive pressure on the existing university and nearby neighborhoods' road networks.

Table 1. Projected increases of population and land use in KSU Campus from 2011 to 2027

\begin{tabular}{llll}
\hline Item & $\mathbf{2 0 1 1}$ & $\mathbf{2 0 2 7}$ & Difference \\
\hline Male Students & 34000 & 40000 & 6000 \\
Female Students & 0 & 27000 & 27000 \\
Employees & 9600 & 26200 & 16600 \\
Faculty Members & 3000 & 5000 & 2000 \\
Dwelling Units & 1100 & 7840 & 6740 \\
Athletics & 0 & 3400 & 3400 \\
Total Floor Area & 1.0 million sq. m & 3.8 million sq. m & 2.8 million sq. m \\
Parking Lots & 16000 & 54000 & 38000 \\
Total Pop. & 46000 & 136000 & 90000 \\
\hline
\end{tabular}

Source: Deputy for Projects Studies modified by the author. 


\subsection{Data Collection \& Traffic Surveys}

Automatic Traffic Counts conducted on KSU roads showed that Mondays have the highest daily traffic volumes (Deputy for Projects, 2011). The following Figure 2 exhibits the total daily traffic volumes that enter and exit the university through its five main gates during a typical Monday.

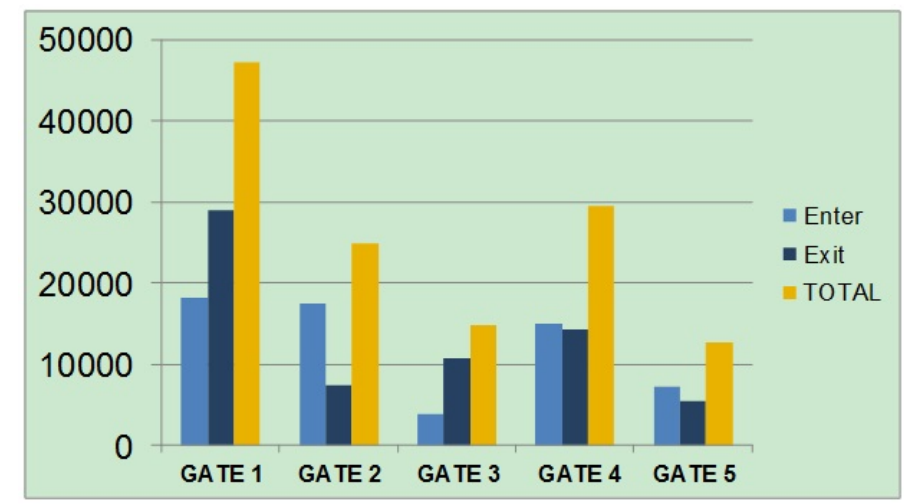

Figure 2. Daily traffic volumes on KSU main gates (2008)

The total number of vehicles that enter and exit the KSU Campus through the five gates was 129000 per day. Nearly $56 \%$ of the traffic uses Gates 1 and 2, which has a strong impact on the road sections located in the southern and western parts of the campus. These sections support more than 17000 vehicles / day / direction generated from the academic and medical buildings (Deputy for Projects, 2011). Meanwhile, the location of important parking capacities on the west side of these buildings explains why these road sections are more congested than the remaining roads.

Traffic pressure on KSUC roads has become eminent during the last couple years. Table 2 shows a comparative study of traffic volumes on key KSUC locations. It shows that traffic volumes have increased by more than $20 \%$ between 2008 and 2010 in one of the road direction (onward) leading to prime KSU facilities. The other direction (outward) shows a modest increase of $3 \%$ during the same period. In some road segments, the increase was magnificent. Some road segments have experienced $100 \%$ increase in traffic volumes while, in other locations, the drop was more than $50 \%$ of traffic, due to road closures and construction rerouting.

Table 2. Traffic counts at selected KSUC locations (2008-2010)

\begin{tabular}{|c|c|c|c|c|c|c|}
\hline \multirow[t]{2}{*}{ Location } & \multicolumn{2}{|c|}{ Onward } & \multirow[t]{2}{*}{$\%$ Change } & \multicolumn{2}{|c|}{ Outward } & \multirow[t]{2}{*}{$\%$ Change } \\
\hline & 2008 & 2010 & & 2008 & 2010 & \\
\hline East Gate \# 4 & 15066 & 22214 & $47.4 \%$ & 14350 & 17617 & $22.8 \%$ \\
\hline Ring Road east & 7835 & 11041 & $40.9 \%$ & 7186 & 10286 & $43.1 \%$ \\
\hline Ring Road South & 5278 & 11664 & $121.0 \%$ & 3910 & 6104 & $56.1 \%$ \\
\hline Ring Road west & 10850 & 11215 & $3.4 \%$ & 9695 & 9693 & $0.0 \%$ \\
\hline Ring Road NW & 11248 & 11153 & $-0.8 \%$ & 8354 & 5544 & $-33.6 \%$ \\
\hline Service Gate \# 3 & 10828 & 8467 & $-21.8 \%$ & 3191 & 2612 & $-18.1 \%$ \\
\hline Ring Road North & 11058 & 9485 & $-14.2 \%$ & 10909 & 8475 & $-22.3 \%$ \\
\hline North Entrance & 6632 & 7098 & $7.0 \%$ & 5087 & 6825 & $34.2 \%$ \\
\hline North Gate \# 5 & 7250 & 11264 & $55.4 \%$ & 5420 & 9301 & $71.6 \%$ \\
\hline Ring Road RTV area & 7845 & 8647 & $10.2 \%$ & 7773 & 3911 & $-49.7 \%$ \\
\hline Ring Road NE & 9419 & 11551 & $22.6 \%$ & 9197 & 7939 & $-13.7 \%$ \\
\hline Book Gate \# 1 & 8517 & 10730 & $26.0 \%$ & 6463 & 6262 & $-3.1 \%$ \\
\hline TOTAL & 111826 & 134529 & $20.3 \%$ & 91535 & 94569 & $3.3 \%$ \\
\hline
\end{tabular}

Source: Deputy for Projects studies recalculated by the author. 
Travel behavior of KSU students and employees show the total dominance of vehicular travel over other modes (Deputy for Projects, 2008). Nearly 91\% of employees' trips used private automobiles; while the remaining was by taxis with minimal walking and public transportation trips. The share of private automobiles trips for students is less severe as it amounts to $83 \% .12 \%$ of trips are by walking from the nearby in-campus student housing while the remaining $5 \%$ are by taxis.

\section{Dealing with the Transportation Problem}

\subsection{Key Results}

The previous analyses of traffic conditions with the KSUC show the growing problem of traffic congestion within and around the campus. In particular, the study shows the following results:

1) Traffic Volumes have increased significantly during the last five years.

2) There is a cute shortage in parking spaces near the academic core $\&$ the medical city.

3) Parking spaces have increased but still far from the expected future demand of 54000 spaces.

4) Negligible role of public transport to/from KSUC, while limited shuttle services are in operation for some college students.

5) Limited internal pedestrian trips, especially between colleges and other university services.

King Saud University has to tackle the transportation problem facing it today and in the future. There is a need to devise proactive policies to tackle future transportation problems as they would intensify in the near future. To achieve the desired KSU strategic policies, there is a need to adopt sustainable policy solutions. These policies shall include the following:

1) Link KSU transportation plans to the city plan to integrate policies and coordinate future actions.

2) Develop a multi-modal Network strategy for external \& internal trips. This strategy should incorporate the most advantageous combination of parking, circulation, transit, and ITS projects for implementation at KSUC.

No amount of capacity enhancement can reduce parking problems and provide safe and orderly movement of traffic, unless the University adopts a sustainable approach to transportation policies. Sustainable university plans in urban areas should be closely linked to city-wide sustainable plans to achieve the desired objectives. Most KSU projects rely on adding more roads and parking capacities to alleviate congestion and solve transportation problems. These efforts may create short-term relieves to campus internal traffic but exaggerate traffic problems in surrounding streets and communities. There is a need to adopt a balanced approach for traffic supply and demand management to deal with transportation issues within and near campuses (HDR, 2012; Kaplan \& Clapper, 2007).

Sustainable transportation policies have become an essential tool to deal with campus transportation issues in most world class universities. Universities need to ascertain their faculty, students, staff, prospective customers and the community at large that efficient and effective university transportation systems are one of its major strategic objectives. Such polices would lead to a better university environment, an enhanced accessibility and mobility of users, a viable campus and sustainable resources. Similarly, small scale solutions and initiatives prove to be effective in relieving localized congestion within and around university campuses.

To achieve these objectives, this study recommends three policy initiatives for consideration by the University policy makers. They are traffic management policies, parking management policies and transportation and community policies.

\subsection{Recommended Policies}

Universities quest for world prominence and to satisfy their constituents have encouraged universities to adopt a sustainable approach to their transportation and development policies. However, sustainable campus development can result in considerable costs to the university at large (Norton, et al., 2007). The call for sustainable mobility is gaining popularity worldwide for small and large communities including major universities' campuses (UN-Habitat, 2013; Truffer, et al., 2002; Comstock, 2009; Norton, et al., 2007; HDR, 2012). The following sections present this research recommended policies to deal with growing problems of campus traffic at KSUC and other world universities.

\subsubsection{Traffic Demand Management Policies}

Most universities rely on traffic demand management techniques to relieve perspective traffic congestion. The adoption of these techniques has resulted in a noticeable decrease of automobile trips for the benefit of 
non-automobile trips within the campus (Bunt Associates, 2013; Kaplan \& Clapper, 2007; Stanford University, 2010).

Firstly, the adoption of campus-wide public transportation systems to link surrounding communities to the university and connect university's major uses can result in a significant reduction of automobile trips. Various studies show the positive contribution of public transportation in enhancing campus accessibility and reducing automobile trips to/from and within the campus (HDR, 2012; Durr, 2011). These systems are often fully or partially subsidized by universities (TCRP, 2001). Nearly 50\% of universities surveyed by TCRP study in 2001 provide directly public transit services (mainly buses), while the others benefit from systems provided by transit agencies and/or municipal entities. Those whom don't provide the service tend to subsidize transit tickets to students and staff to encourage them to use transit services (TCRP, 2001).

Second, there is a need to encourage walking as a primary internal trip mean of travel within the campus for students and staff. This can be achieved by considering the safety and wellbeing of pedestrians within the campus (Davis, 2011; Kaplan \& Clapper, 2007). Safe and protected routes, clear signage and direct access pathways are essential ingredients for a pedestrian friendly environment.

Third, many universities have encouraged the adoption of campus ridesharing programs for students and staff. These programs have proven to be effective in reducing single occupancy automobiles (Zalkow \& Renkens, 2010; Lieb, 2011). This will relieve campus congestion and reduce the need to provide additional parking spaces within the campus.

Fourth, managing the transportation system requires the presence of controlling entity that sets and enforces regulations related to transportation mode usages (Kaplan \& Clapper, 2007). The board/department would develop and implement congestion mitigations plans to address known traffic events on campus. Further, the transportation department/board should evaluate the full impact of building expansions prior to construction. Traffic impact studies should be required for all planned big projects to define the needed mitigation measures to these projects.

Fifth, the university could utilize a flex time approach to its classes and employees. Staggering class hours and work times would redistribute travel peaks to a longer period thus relieving traffic pressures within and around the campus and campus parking usage.

Sixth, universities rely ore increasingly on advances in transportation technologies to manage and control travel modes with the campus. KSU needs to pursue technologies to use and operate the existing roadway network efficiently and manage its future public transit systems (e.g. Intelligent Transportation Systems (ITS)) (Truffer, et al. 2002; Mallia, 2011).

Finally, there is a need to provide adequate and appropriate signage on campus to make certain that students, faculty, staff, hospital patients, and visitors can safely reach their destinations, especially when time is critical. Better signage will help university users reach their destinations easily thus releasing road space to other users (Kaplan \& Clapper, 2007). Further, better directional signage would encourage walking and other non-motorized trips as it reduces uncertainty in trip length and time and create a friendly environment to all users.

\subsubsection{Parking Management Policies}

The concept of parking management system can be very effective in reducing the increasing parking needs within campuses. Valuable lands are occupied with cars which constitute an inefficient way to land utilization especially surface parking. Many universities are embarking strict parking regulations that emphasize the gradual reduction of parking spaces and the continuous increase in parking fees especially in urban areas (Zalkow \& Renkens, 2010; University of BATH, 2003).

However, in growing universities there is still a need to provide adequate parking lots for new facilities to reduce the pressure on existing lots. This needs to be complemented with enhancements in parking lot design and the provision of pedestrian routes to and through lots to ease pedestrian access and reduce walk trip lengths. Similarly, successful universities systems tend to provide adequate way-finding signage on campus to direct motorists to appropriate parking areas (HDR, 2012; Kaplan \& Clapper, 2007). They also emphasize the provision of variable message signs inside and outside parking lots to easily inform motorists of the status of parking lots within the campus and ease spaces' accessibility to drivers.

Finally, with the successful implementation of sustainable transportation systems, some of the existing parking lots, especially in central locations, could be converted to other uses needed for the future activities. 


\subsubsection{Transportation and Community Policies}

There is a need to enhance the linkage between land use and transportation. This integrated approach will shift focus from land use designation of buildings to the realization of people's and activities' needs in most efficient manner (UN habitat, 2013). It also will help create a mixed land use of shops, restaurants, and specialized services in better accessible locations for students, staff and visitors. The creation of a livable environment has become a strategic goal for many campuses.

KSU needs to emphasize the provision of shuttle services between residential areas (faculty housing and student dorms) and core areas of campus such as the academic area, cultural and health facilities within the campus. Meanwhile, the university should create an environmental friendly environment that rely on protected pathways, community gardens and thriving plazas to encourage campus residents and visitors to experience the campus on foot.

Finally, the university may demonstrate a strong organizational commitment to reduce private automobile dependence through leadership by example. Faculty and staff should work together to establish, advocate and implement initiatives that encourage the utilization of other modes to travel to/from and within the university to encourage students and visitors to follow suit in the near future. The use of park-n-ride facilities for students and staff living outside the university is crucial for the future success of university transportation policies. These policies are related to demand management and the reduction of vehicular space needed within the campus (HDR, 2012; Petee, 2011).

\section{Concluding Remarks}

Analysis of KSUC as a case study has shown the potentially significant influence of massive construction projects on its transportation system. Unless dealt with in a sustainable approach, transportation challenges facing KSU are dreadful. Without proper and timely intervention on future transportation systems, KSU campus would experience serious problems related to safety, traffic congestion, pollution, and parking shortages. For a more sustainable campus, KSU has to adopt a balanced transportation system. The new system should not be based solely on improving vehicular circulation and parking provisions but should enhance public transportation and pedestrian environment within the campus. The university should embark new sustainable policies to curtail demand on vehicular trips and parking spaces. University users need to increasingly rely on environmental-friendly modes of travel, such as walking and public transportation means of travel, internally and externally. Finally, the university should target the inclusion of ITS in all aspects of its transportation system to help manage and enhance it.

In the wider context, universities worldwide are facing similar transportation challenges with different scales. Urban development pressures inside and outside current campuses are exerting large impacts on the efficiency of the city and its transportation systems.

\section{References}

Al-Fawzan, S. (2004). Evaluation and Improving Traffic at the Entrances of KSU Campus During Peak Hours. Journal of King Saud University - Architecture and Planning, 16.

Al-Jowair, I. (2006). The role of roads, streets, and intersections' design in increasing traffic-circulation problems: The Case of King Saud University Campus. Journal of King Saud University - Architecture and Planning, 19.

Al-Mansour, A., \& Zaho, M. (2004). Evaluation and Planning Vehicles Parking Areas in King Saud University Campus. Research Center, College of Engineering, King Saud University.

Anani, B., Al-Suhaibani, A. R., \& Al-Mudaiheem, J. (1989). Improving Traffic Operations at King Saud University during Peak Hours. Research Center, College of Engineering, King Saud University.

Bovia, H. (2011). Coming Together to Create an Alternative Transportation Program: The Stone Soup Approach. Association for the Advancement of Sustainability in Higher Education: 2011 Conference Proceedings.

Bunt \& Associates. (2013). 2012 Campus Traffic Survey: University of Victoria. Project no. 5070.04.

Burgstahler, S., \& Cory, R. (2008). Universal Design in Higher Education: from Principles to Practice. Harvard Education Press: Cambridge, MA.

Comstock, K. (2009). Small Town Approach to Sustainable Transport. City of Franklin, TN.

Coulson, J. et al. (2011). University Planning and Architecture: The Search for perfection. Routledge: New York.

Davis, M. (2011). The Strategic Mobility Plan for Campus Sustainability in Transportation. Association for the Advancement of Sustainability in Higher Education: 2011 Conference Proceedings. 
Deputy for Projects, KSU. (2006). Traffic Impact Study for the New Girls' Campus. Wilbur Smith Associates: Riyadh.

Deputy for Projects, KSU. (2008). The Comprehensive Study of Parking \& Traffic at KSU. Katteb \& Alami: Riyadh.

Deputy for Projects, KSU. (2009). Master Plan Update for King Saud University Campus. HOK: Riyadh.

Deputy for Projects, KSU. (2011). Master Plan for King Saud University Medical City. HOK: Riyadh.

Durr, E. (2011). Establishing a Service Bus Route to Meet Student and Community Needs. Association for the Advancement of Sustainability in Higher Education: 2011 Conference Proceedings.

HDR Engineering. (2012). 2012 Campus Mobility Plan: Final Report. prepared for the North Carolina State Transportation.

Hendricks, S. (2011). Changing Travel behavior One trip at a Time: Meeting the Challenge of the Large Suburban Campus. Association for the Advancement of Sustainability in Higher Education: 2011 Conference Proceedings.

Kaplan, D., \& Clapper, T. (2007). Traffic Congestion on a University Campus: A Consideration of Unconventional Remedies to Nontraditional transportation Patterns. Planning for Higher Education, 36(1), 28-39.

Lieb, D. (2011). SOVs Are So Over: Creating a Community-Wide Rideshare Program. Association for the Advancement of Sustainability in Higher Education: 2011 Conference Proceedings.

Mallia, M. E. (2011). Destination Green: Its Within Reach. Association for the Advancement of Sustainability in Higher Education: 2011 Conference Proceedings.

Norton, R. et al. (2007). Transforming the University campus into a Sustainable Community. Planning for Higher Education, 35(4), 22-39.

Petee, L. (2011). Connecting the Community College to the Community: Collaboratives for Green Transportation. Association for the Advancement of Sustainability in Higher Education: 2011 Conference Proceedings.

Slade, J. (2010). Promoting Bicycle Commuting on Campus. Association for the Advancement of Sustainability in Higher Education: 2010 Conference Proceedings.

Stanford University. (2010). Sustainable Transportation at Stanford University: The Role of TDM. Association for the Advancement of Sustainability in Higher Education: 2010 Conference Proceedings.

TCRP (Transit Cooperative Research Program). (2001). Transportation on Colleges and University Campuses: A Synthesis of Transit Practice. TRB: Washington.

Time Magazine, June 10, 2013, P.31.

Toor, W., \& Halvlick, S. (2004). Transportation \& Sustainable Campus Communities: Issues, Examples, Solutions. Island Press: Washington.

Truffer, B. et al. (2002). Experimenting for Sustainable Transport: The Approach of Strategic Niche Management (Transport, Development and Sustainability Series).

UN Habitat. (2013). Planning and design for Sustainable Urban Mobility: Global Report on Human Settlement 2013. UN Habitat: Washington.

University of BATH. (2003). University of BATH Transport Strategy. University of BATH: BATH, UK.

Zalkow, D., \& Renkens, S. (2010). Sustainable Transportation Planning at an Urban University. Association for the Advancement of Sustainability in Higher Education: 2010 Conference Proceedings.

\section{Note}

Note 1. Inauguration times for these universities were extracted from Time Magazine (June 10, 2013 issue).

\section{Copyrights}

Copyright for this article is retained by the author(s), with first publication rights granted to the journal.

This is an open-access article distributed under the terms and conditions of the Creative Commons Attribution license (http://creativecommons.org/licenses/by/3.0/). 